\title{
Utilization of personal protective equipment and associated factors among large-scale factory workers using health belief model in Debre-Berhan town, Amhara region, Ethiopia, 2021
}

\section{Wondimu Sema}

Debre Berhan University health science college

Muluken Tessema ( $\nabla$ mklitmuluken@gmail.com )

DBU: Debre Berhan University https://orcid.org/0000-0001-6222-3902

\section{Research}

Keywords: Personal protective equipment, Health belief model, Factory workers

Posted Date: September 21st, 2021

DOl: https://doi.org/10.21203/rs.3.rs-910445/v1

License: (c) (1) This work is licensed under a Creative Commons Attribution 4.0 International License. Read Full License 


\section{Abstract}

\section{Background}

Personal protective equipment is designed to protect workers from serious workplace injuries or illnesses resulting from contact with chemical, radiological, physical, electrical, mechanical, or other workplace hazards.

\section{Objective}

To determine Personal Protective Equipment utilization and its associated factor based on health belief model among large scale factory workers in Debre-Birhan, Ethiopia.

Methods

An institution-based cross-sectional study was employed in Debre Berhan Town, North Shoa Ethiopia from April 1 st to May 1 st , 2021 using an interviewer administered structured questionnaires. A total of 412 samples were selected by systematic random sampling method. The data was entered by Epi-data version 3.1 and analyzed by SPSS. variables with a p-value of 0.2 was fitted for multiple logistic regressions and a $p$-value of $<0.05$ was statistically significant.

Result

A total of 412 workers were participated in the study with a $100 \%$ response rate. The mean age was 29 $( \pm 7.3)$ years. Most workers $367(89 \%)$ knew that PPE can prevent work related injury and illness. Over all $172(41.7 \%)$ of the workers were considered to have good PPE utilization. Perceived susceptibility [AOR=1.2, $95 \%, \mathrm{Cl}$ (1.076-1.38)], perceived severity, [AOR=1.1, $95 \%, \mathrm{Cl}$ (1.088-1.163)], perceived selfefficacy, [AOR=1.2, $95 \%, \mathrm{Cl}(1.082-1.349)]$, and Perceived barrier [AOR=0.87, $95 \%, \mathrm{Cl}(0.800-0.956)$ ] were found to be significant predictors of good PPE utilization.

Conclusion

The study revealed that good Personal protective equipment utilization in large scale factory workers. Perceived susceptibility perceived severity, perceived barrier and perceived self-efficacy were found to be predictors of PPE utilization.

\section{Introduction}

Personal protective equipment is designed to protect workers from serious workplace injuries or illnesses resulting from contact with chemical, radiological, physical, electrical, mechanical, or other workplace hazards. It may include items such as gloves, safety glasses and shoes, earplugs or muffs, hard hats, respirators, or coveralls, vests and full body suits[1]. It is a significant determining factor between an accident and safety in the working environment. Evidence suggests that wearing the correct personal 
protection at all times is extremely important in reducing accidents and should be given high priority[2]. Globally, $34 \%$ of occupational accidents were resulting from the lack of use of PPE available at workplace at the time of the accident. In addition, $13 \%$ of work-related accidents result from the inappropriate use of PPE[3].

While the use of personal protective equipment has been identified as an important hazard control strategy in work environments where it may not be practical to adopt other strategies, there is a great concern however that PPE usage remains low[4]. Evidences indicated that workers use of PPE is influenced by various factors. It has been reported that the influencing factors include Socio-demographic factors, perception about Occupational disease and Expectations of the benefits and Barriers of PPE use[5, 6].

In Ethiopia, reports indicated that only 5 to $10 \%$ of workers have access to occupational health services in their respective workplaces[7]. But nearly half [44.66\%] of the workers in Ethiopia were experienced occupational injury. Upon reviewing several literatures about occupational health and safety among factory workers for this study, the PPE utilization rate typically ranges between $20.6 \%$ and $82.4 \%$ [7-10].

\section{Methods}

\section{Study design, area and period}

An institutional based cross-sectional quantitative study design was employed. from April 1st to May 1st, 2021 in Debre Birhan North Shoa, Amhara region Ethiopia. Based on CSA estimation the town has a total population of 114,652 , of whom 51,843 are men and 62,809 women. It is located approximately $130 \mathrm{~km}$ northeast of the capital Addis Ababa and has a total of 22 large scale factories. These factories are mainly involved in the production of processed food, textile, beverage, glass and other products. The town is one of the preferred investment destinations in the country. This study was conducted at selected large scale factories found in Debre Birhan Town.

\section{Source Population}

All large scale factory workers in Debre Birhan town were considered as a source populations. Study Population

Factory workers working in the selected factories in Debre Birhan town who were meet the inclusion criteria.

\section{Study Unit}

Selected factory workers working in the selected factories in Debre Birhan town who were meet the inclusion criteria.

\section{Inclusion Criteria}


All factory workers that were present at work during the study period were considered for the study.

\section{Exclusion criteria}

Factory workers working in quality control and finishing section in beer and blanket factories respectively.

\section{Sample size determination}

The Sample size for the dependent variable was calculated using single population proportion formula based on the following assumptions. Utilization of PPE was taken from a study done at Kombolcha textile factory which was $58.2 \%$ [16], Level of confidence $95 \%$, margin of error $5 \%$ non-response rate $10 \%$ and gives a sample size of 412 . Similarly, for associated factors, by taking significantly associated variables with multivariate analysis in different studies, the sample size is calculated by using Epi Info 7 STATCAL software, cohort or cross sectional study.

\section{Sampling technique and procedure}

A total of 22 large scale factories in Debre-Birhan town were considered for sampling. Based on the assumption of $30 \%$ representativeness 7 factories were selected by simple random selection method. Before the data collection was started all the necessary PPE for the workers working in different sections of the factory was identified based on literatures[45, 46]. Workers utilizing the similar type of PPE were considered for this study. The required sample size was taken proportional to the size of the selected factories. To get the individual sample at the selected factory systematic random sampling was conducted by using the total number of factory workers who have worked during the study period and number of sample required in each selected factory. After getting the sampling fraction in the selected factory the first participant was obtained by lottery method among the first "k" units.

\section{Data Collection Method}

Interviewer administered structured questionnaire was used to collect the required quantitative information on utilization and determinates of PPE use. Questionnaire is developed after review of similar literatures $[16,17,28]$. It includes: socio-demographic characteristics of the workers, knowledge about PPE \& occupational exposures and seven HBM construct measures, namely: perceived susceptibility of occupational-related health problems, Perceived severity of occupational-related health problems, perceived benefits of using PPE, perceived barriers to using PPE, perceived self-efficacy of using PPE, and cues to action of using PPE. The constructs of HBM was answered on a 5-point Likert's scale [1 = strongly disagree; 5 = strongly agree]. The score of each participant was summed to get a score for each construct.

The questionnaire is prepared in English and translated to Amharic. The required data was collected by Four Environmental health professionals. Training was provided for data collectors on different issues regarding the research.

\section{Data Processing and Analysis}


The collected data was checked for its completeness manually; data entry was done using Epi-data version 3.1. The entered data was exported to SPSS version 21 for further cleaning and analysis. Data editing, coding, checking and organization was done to transform the data into format suitable for further analysis. The model fitness was checked by Hosmer Lomeshow goodness of fit test. Assumptions of model including Multicollinearity and outlier were checked by variance inflation factor [VIF] and normal P$P$ plot respectively. All independent variables were fitted separately into binary logistic regression model to evaluate the degree of association with utilization of PPE. The variables with a p-value $<0.20$ was fitted to multiple logistic regression model. Then, AOR value with $95 \% \mathrm{Cl}$ was calculated to identify independent variables which were significantly associated with PPE utilization, a p-value $<0.05$ was used as level of significance for the final qualifiers as factors associated with PPE utilization.

\section{Results}

\section{Socio-demographic characteristics of factory workers}

A total 412 factory workers were involved in this study with $100 \%$ response rate. As shown in table 1 below the participants were predominantly male [66.3\%]. The age of the participants were ranged from 18 to 57 with the mean age of 29.4[ \pm 7.3$]$ years. Majority of [97.3\%] the participants were employed on a permanent basis with a small percentage of temporary workers 11 [2.7\%]. Concerning marital status of the workers $47.3 \%$ were married [Table-1].

Table 1. Socio-demographic characteristics of large scale factory workers in Debre-Birhan, town Ethiopia. June, 2021 


\begin{tabular}{|c|c|c|c|}
\hline Variable & Categories & Frequency & Percent \\
\hline \multirow[t]{2}{*}{ Sex } & Male & 273 & $66.3 \%$ \\
\hline & Female & 139 & $33.7 \%$ \\
\hline \multirow[t]{3}{*}{ Age } & $18-28$ & 220 & 53.4 \\
\hline & $29-39$ & 140 & 34.0 \\
\hline & $>39$ & 52 & 12.6 \\
\hline \multirow[t]{4}{*}{ Educational level } & Primary & 10 & 2.4 \\
\hline & Secondary & 69 & 16.7 \\
\hline & Diploma & 203 & 49.3 \\
\hline & First degree and above & 130 & 31.6 \\
\hline \multirow[t]{3}{*}{ Marital status } & Married & 195 & 47.3 \\
\hline & Single & 213 & 51.7 \\
\hline & Others ${ }^{a}$ & 4 & 0.9 \\
\hline \multirow[t]{2}{*}{ Employment form } & Temporary/ contract/ & 11 & 2.7 \\
\hline & Permanent & 401 & 97.3 \\
\hline \multirow[t]{3}{*}{ Working experience } & $<5$ & 321 & 77.9 \\
\hline & $5-10$ & 60 & 14.6 \\
\hline & $>10$ & 31 & 7.5 \\
\hline \multirow[t]{4}{*}{ Income } & $500-2500$ & 151 & 36.7 \\
\hline & $2501-4500$ & 118 & 28.6 \\
\hline & $4501-6500$ & 127 & 30.8 \\
\hline & $>6501$ & 16 & 3.9 \\
\hline
\end{tabular}

NB- a- [widowed and divorced]

\section{PPE Utilization Status}

Overall, $41.7 \%$ [95\% Cl, 37.1-46.1] of the factory workers had good PPE utilization. The utilization was highly varied among the type of PPE. Respirator was found to be the most utilized PPE with a mean utilization score of $3.94 \pm 1.42$ followed by coverall. On the other hand ear protector [1.14 $\pm 1.0 .6]$ was found to be the least utilized PPE. Helmet, Eye protector, coverall, safety shoe, glove had a mean utilization score of $2.11 \pm 1.26,2.53 \pm 1.6,3.42 \pm 1.7 ; 2.95 \pm 1.82$ and $2.41 \pm 1.64$ respectively [Table 2]. 
Table 2 PPE utilization frequency score of large scale factory workers in Debre-Birhan Town, Ethiopia. June, 2021.

\begin{tabular}{|llllllll|}
\hline \multirow{2}{*}{ Type of PPE } & \multicolumn{2}{l}{ Frequency [\%] } & & & & Mean & SD \\
\cline { 2 - 8 } & Never & Rarely & Sometimes & Often & Always & & \\
\hline Helmet & $178[43.2]$ & $105[25.5]$ & $69[16.7]$ & $25[6.1]$ & $35[8.5]$ & 2.11 & 1.26 \\
\hline Eye protector & $160[38.8]$ & $103[25]$ & $30[7.3]$ & $10[2.4]$ & $109[26.5]$ & 2.53 & 1.63 \\
\hline Ear protectors & $385[93.4]$ & $14[3.4]$ & $2[0.5]$ & $4[1]$ & $7[1.7]$ & 1.14 & 0.62 \\
\hline Respirator & $53[12.9]$ & $22[5.3]$ & $46[11.2]$ & $67[16.3]$ & $224[54.4]$ & 3.94 & 1.42 \\
\hline Coverall & $85[20.6]$ & $86[20.9]$ & $21[5.1]$ & $10[2.4]$ & $210[51]$ & 3.42 & 1.71 \\
\hline Safety shoe & $168[40.8]$ & $32[7.8]$ & $27[6.6]$ & $24[5.8]$ & $161[39.1]$ & 2.95 & 1,82 \\
\hline Glove & $215[52.2]$ & $17[4.1]$ & $60[14.6]$ & $35[8.5]$ & $85[20.6]$ & 2.41 & 1.64 \\
\hline
\end{tabular}

\section{Knowledge towards PPE utilization}

In this study 367 [89\%] of workers knew that PPE can prevent work related injury and illness, of them 164 [39.8\%] were good PPE utilization. Generally in this research 342[83\%] of factory workers had good knowledge about PPE, while the remaining $70[17 \%]$ of workers had poor knowledge regarding PPE utilization.

\section{Perception towards occupational disease and PPE utilization}

Concerning perception of workers towards PPE utilization and occupational disease, it was measured using HBM constructs and treated as a continuous variable as shown in table 4 and 5 below. The mean score of Perceived Susceptibility was found to be 17.1[ \pm 8.7$]$. For Perceived severity possible values ranging from 7 to 35 and the mean score was 20.2[ \pm 11.4$]$. In addition the mean scores of Perceived benefit, Perceived barrier, Cues to action, Perceived self- efficacy was found to be 10.5[ \pm 5.8$], 22.0[ \pm 9.3]$, $29.2[ \pm 8.9], 15.7[ \pm 7.6]$ respectively.

Table 3. Health belief model construct response of factory worker in Debre-Birhan Town, Ethiopia, June, 2021. 
HBM Constructs

Strongly Disagree Neutral Agree

Strongly

Disagree

agree

Perceived Susceptibility

$\mathrm{F}[\%]$

$\mathrm{F}[\%]$

$\mathrm{F}[\%]$

$\mathrm{F}[\%]$

$\mathrm{F}[\%]$

It is extremely likely I will get

occupational illness or injury in the

$122[29.6]$

$87[21.1]$

$51[12.4] \quad 40[9.1]$

$112[27.2]$

future.

I think my chance of developing

occupational illness is grate

There is a good possibility I will get occupational illness in the next few years.

I know predecessors in this career field who got an occupational illness

I think small exposures to occupational chemicals or noise will lead me to an illness.

I am more likely than the average worker to have occupational illness or injury
$83[20.1] \quad 122[29.6] \quad 60[14.6] \quad 35[8.5] \quad 112[27.2]$

$\begin{array}{lllll}77[18.7] & 98[23.8] & 40[9.7] & 115[27.9] & 82[19.9]\end{array}$

$115[27.9] \quad 92[22.3] \quad 47[11.4] \quad 23[5.6]$

$135[32.8]$

$139[33.8] \quad 81[19.7] \quad 4[1.0] \quad 84[20.4] \quad 104[25.2]$

$152[36.9] \quad 115[27.9] \quad 16[3.9] \quad 21[5.1] \quad 108[26.2]$

\section{Perceived severity}

The thought of getting an occupational illness is deeply concerns me

If I developed an occupational illness, my career would be in danger

Problems I would experience from an occupational illness would last a life time

An occupational illness will lead to permanent changes in my health

My financial security would be endangered if I developed an occupational illness

I believe I could die prematurely if I developed an occupational illness

I am afraid to even think about getting an occupational illness
$163[39.6] \quad 92[22.3] \quad 16[3.9] \quad 15[3.6] \quad 126[30.6]$

$157[38.1] \quad 50[12.1] \quad 13[3.2] \quad 16[3.9] \quad 176[42.7]$

$\begin{array}{lllll}73[17.7] & 139[33.7] & 9[2.2] & 49[11.9] & 142[34.5]\end{array}$

$204[49.5] \quad 54[13.1] \quad 5[1.2] \quad 19[4.6] \quad 130[31.6]$

$146[35.4] \quad 56[13.6] \quad 19[4.6] \quad 13[3.2] \quad 178[43.2]$

$\begin{array}{lllll}131[31.8] & 89[21.6] & 7[1.7] & 33[8.0] & 152[36.9]\end{array}$

$85[20.6] \quad 131[31.8] \quad 29[7.0] \quad 2[0.5] \quad 165[40]$ 
Wearing PPE will prevent me from occupational illness

PPE prevents exposure to the kinds of hazards you are around on the job

I worry about getting an occupational illness when I don't wearing PPE

I benefit by wearing PPE
$188[45.6]$

$61[14.8]$

$16[3.9]$

$66[16]$

81[19.7]

$112[27.2]$

$116[28.2]$

$43[10.4]$

$60[14.6]$

81[19.7]

$144[35]$

$120[29.1]$

$15[3.6]$

$33[8.0]$

100 [24.3]
$131[31.8]$

$12[2.9]$

30[7.3]

121[29.4] 


\section{Perceived barriers}

When I wear PPE I feel uncomfortable $\quad 136[33.0] \quad 21[5.1] \quad 11[2.7] \quad 142[34.5] \quad 102[24.8]$

When I wear PPE, it interferes with my $\quad 124[30.1] \quad 74[18.0] \quad 12[2.9] \quad 107[26.0] \quad 95[23.1]$ ability to do my job

PPE is not always available to me

When I wear PPE co workers would make fun of me

My supervisor is aware of my compliance with PPE guidelines

I would need to develop a new habit for wearing PPE, and that is difficult to me

Wearing PPE is just too inconvenient for you

$\begin{array}{lllll}\text { 115[27.9] } & 66[16.0] & 11[2.7] & 138[33.5] & 82[19.9] \\ 85[20.6] & 107[26.0] & 7[1.7] & 74[18.0] & 139[33.7]\end{array}$

$66[16.0] \quad 70[17.0] \quad 14[3.4] \quad 118[28.6] \quad 144[35.0]$

$80[19.4] \quad 113[27.4] \quad 16[3.9] \quad 80[19.4] \quad 123[29.9]$

$48[11.7] \quad 158[38.3] \quad 12[2.9] \quad 58[14.1] \quad 136[33.0]$

\section{Cues to action}

A reminder from my supervisor everyday would be important to wear of PPE

My supervisor checking on me would improve you to wear of PPE

My employer is important for wearing PPE

Posters in my factory would serve as important reminders to wear PPE

The threat of disciplinary action is an important factor in ensuring I wear PPE

Having PPE at location of hazard is critical to ensure that I wear it

If you see others wearing PPE in your area, then it reminds you to use it

Regular and frequent education on the importance of PPE improves how often I wear it

My supervisor sets the example on wearing PPE when being exposed to hazard

\section{Self-efficacy}

I am confident that I remember to use PPE when I am exposed to hazards at

$135[32.8] \quad 30[7.3] \quad 97[23.5] \quad 54[13.1] \quad 96[23.3]$

$33[8.0] \quad 109[26.5] \quad 73[17.7] \quad 89[21.6] \quad 108[26.2]$

$25[6.1] \quad 93[22.6] \quad 90[21.8] \quad 95[23.1] \quad 109[26.5]$

$46[11.2] \quad 92[22.3] \quad 46[11.2] \quad 105[25.5] \quad 123[29.9]$

$66[16.0] \quad 72[17.5] \quad 86[20.9] \quad 96[23.3] \quad 92[22.3]$

$72[17.5] \quad 62[15.0] \quad 54[13.1] \quad 123[29.9] \quad 101[24.5]$

$110[26.7] \quad 24[5.8] \quad 62[15.0] \quad 65[15.8] \quad 151[36.7]$

$86[20.9] \quad 70[17.0] \quad 38[9.2] \quad 46[11.2] \quad 172[41.7]$

$77[18.7] \quad 113[27.4] \quad 40[9.7] \quad 32[7.8] \quad 150[36.4]$

$108[26.2]$

$89[21.6]$

$11[2.7]$

$38[9.2]$

$166[40.3]$ 
work

I am confident I can obtain the proper

$101[24.5]$

83[20.1]

40[9.7]

$25[6.1]$

$163[39.6]$

PPE when I am exposed to hazards at work

I am confident that my job

performance will NOT be impacted by

wearing PPE

I am confident that the PPE I use when

I am exposed to hazard is the proper

$104[25.2] \quad 76[18.4] \quad 36[8.7] \quad 19[4.6]$

177[43.0]

equipment to protect my health

I am confident that after wearing the proper PPE throughout my career will

$25[6.1]$

$163[39.6]$

$19[4.6] \quad 24[5.8]$

$181[43.9]$

prevent me from getting an

occupational illness

156[37.9] $17[4.1]$

$7[1.7]$

70[17.0]

162[39.3]

Table 4 Health belief model construct score of large-scale factory worker in Debre-Birhan Town, Ethiopia. June, 2021

\begin{tabular}{|lllllll|}
\hline & $\begin{array}{l}\text { Perceived } \\
\text { susceptibility }\end{array}$ & $\begin{array}{l}\text { Perceived } \\
\text { severity }\end{array}$ & $\begin{array}{l}\text { Perceived } \\
\text { benefit }\end{array}$ & $\begin{array}{l}\text { Perceived } \\
\text { barrier }\end{array}$ & $\begin{array}{l}\text { Cues to } \\
\text { action }\end{array}$ & $\begin{array}{l}\text { Perceived } \\
\text { self- efficacy }\end{array}$ \\
\hline mean & 17.1 & 20.2 & 10.5 & 22.0 & 29.2 & 15.7 \\
\hline Min & 6.00 & 7.00 & 4.00 & 7.00 & 9.00 & 5.00 \\
\hline Max & 30.00 & 35.00 & 20.00 & 35.00 & 45.00 & 25.00 \\
\hline SD & 8.7 & 11.4 & 5.8 & 9.3 & 8.9 & 7.6 \\
\hline
\end{tabular}

\section{Multivariate analysis of associated factors}

Of the total eight potential candidate predictors of PPE utilization of factory workers that were included in the multiple logistic regression model, only four of them [Perceived susceptibility, perceived severity, Self-efficacy and perceived barriers] were found as predictors of PPE utilization [Table 5].

Generally, after controlling possible confounding factors the result of the research indicated that per a unit increases in the total score of perceived susceptibility towards PPE utilization the odds of using PPE was increased by $20 \%$ [AOR=1.2, $95 \%, \mathrm{Cl}$ [1.07-1.38]]. Similarly per a unit increases in the total score of perceived severity towards PPE utilization the odds of using PPE was increased by $10 \%$, [AOR=1.1, $95 \%$, $\mathrm{Cl}$ [1.01-1.16]]. The other variable which independently associated with PPE utilization was Perceived Self-efficacy in which, per a unit increases in the total score of perceived self-efficacy towards PPE utilization the odds of using PPE was increased by 20\%, [AOR=1.2, $95 \%$, CI [1.08-1.34]]. Perceived barrier 
was also found to be a negative predictors of PPE utilization in which per a unit increases in the total score of Perceived barrier towards PPE utilization the odds of using PPE was decreased by $13 \%$, [AOR=0.87, $95 \%, \mathrm{Cl}[0.80-0.95]]$.

Table 5. Multivariate analysis of factors associated with PPE Utilization among factory workers in DebreBirhan town, Ethiopia, June 2021.

\begin{tabular}{|c|c|c|c|c|c|c|c|c|c|}
\hline \multirow[t]{2}{*}{ Variable } & \multirow[t]{2}{*}{ Categories } & \multirow[t]{2}{*}{ COR } & \multicolumn{2}{|l|}{$95 \% \mathrm{Cl}$} & \multirow[t]{2}{*}{ p-value } & \multirow[t]{2}{*}{ AOR } & \multicolumn{2}{|c|}{$95 \% \mathrm{Cl}$} & \multirow{2}{*}{$\begin{array}{l}\text { p- } \\
\text { value }\end{array}$} \\
\hline & & & L & U & & & $\mathrm{L}$ & U & \\
\hline \multirow[t]{2}{*}{ Sex } & Male & 1.43 & .944 & 2.19 & 0.09 & .77 & .26 & 2.28 & .645 \\
\hline & Female & 1.00 & & & & 1.0 & & & \\
\hline \multirow[t]{4}{*}{ Income } & $500-2500$ & .540 & .179 & 1.63 & .274 & .05 & .00 & 56.55 & .421 \\
\hline & $2501-4500$ & .233 & .076 & .717 & .011 & .06 & .00 & 69.48 & .455 \\
\hline & $4501-6500$ & .201 & .066 & .619 & .005 & .06 & .00 & 73.64 & .454 \\
\hline & $>6501$ & 1.00 & & & & 1.00 & & & \\
\hline \multirow[t]{2}{*}{ Knowledge } & Good & 2.58 & 1.43 & 4.64 & .002 & 1.9 & .51 & 7.34 & .332 \\
\hline & Poor & 1.00 & & & & 1.00 & & & \\
\hline $\begin{array}{l}\text { Perceived } \\
\text { susceptibility }\end{array}$ & & 1.465 & 1.364 & 1.573 & $<0.001$ & 1.2 & 1.07 & 1.38 & $.002^{*}$ \\
\hline $\begin{array}{l}\text { Perceived } \\
\text { severity }\end{array}$ & & 1.311 & 1.248 & 1.377 & $<0.001$ & 1.1 & 1.01 & 1.16 & $.012^{\star}$ \\
\hline $\begin{array}{l}\text { Perceived } \\
\text { benefit }\end{array}$ & & 1.059 & 1.024 & 1.095 & 0.001 & 1.05 & .95 & 1.17 & .302 \\
\hline $\begin{array}{l}\text { Perceived } \\
\text { barrier }\end{array}$ & & .713 & .670 & .758 & $<0.001$ & .87 & .80 & .95 & $.003 *$ \\
\hline Self-efficacy & & 1.422 & 1.338 & 1.510 & $<0.001$ & 1.2 & 1.08 & 1.34 & $.001 *$ \\
\hline
\end{tabular}

*-significant at $p<0.05$

\section{Discussion}

The finding of this research indicated that, only 172 [41.7\%] of the workers were considered to have good PPE utilization. This finding was much lower than the study done in Thailand and Addis Ababa, which indicated that [70.1\%] and [64.80\%] of the workers had good PPE utilization respectively [22, 30]. On the contrary the finding of this research was higher than the study done in Gujarat, India that showed only 25 $\%$ of the workers were considered to have good PPE utilization[50]. This difference might be due to 
methodological differences, like study population and methods of data collection, and workplace conditions, employees' level of awareness on hazard control and disease prevention.

The use of PPE varied considerably depending on the item examined with the respirator and coverall being the most commonly used protective items. The finding was inconsistent with the study done in Hawasa town among Wood and Metal Worker that showed eye protector and safety shoe were the most utilized protective items [51]. On the other hand, in this research ear protector was found to be the least utilized type of PPE. The finding was different with the study done in Missouri, USA that indicates helmet was found to be the least utilized PPE type[52]. This difference might be due to the difference in the nature of factories considered in the study.

In this research none of the socio-demographic factors were significant at a $p$ value of $<0.05$. This finding was inconsistence with the study done in different countries. For example a research done in Uganda showed that among the socio-demographic factors sex was found to be a significant predictors of PPE utilization in which Female respondents were used PPE more than male respondent $[A O R]=6.64 ; 95 \% \mathrm{Cl}$ : 1.55-28.46[24]]. Similarly in Nepal Female respondents were used PPE 3.65 times than male [AOR] = $6.64 ; p=0.031][53]$. This difference might be due to the difference in educational level and culture of the participants.

Another socio-demographic factor which was found to be insignificant predictors of PPE utilization was age of the workers. The finding was consistent with the study done in Uganda and Mombasa County, Kenya[24,27]. But finding of this research regarding age was against with different research. For instance a research conducted in Indonesia among a sample of 200 workers indicated that, workers who have the age of greater than 30 years have the possibility to use PPE 7.54 units higher than those below 30 years[54].

Similarly employment form, income, working experience and marital status was among the sociodemographic factors that were not predictors of PPE utilization. Similar finding was obtained from a study conducted in Kenya and Addis Ababa, in which employment form, income, working experience and marital status were not determinate factors of PPE utilization[27, 41].

Regarding the HBM constructs, Perceived susceptibility, perceived severity, Perceived self-efficacy and perceived barriers were significantly associated with PPE utilization. On the other hand perceived benefit and cues to action towards PPE utilization were not found to be independent predictors.

Perceived susceptibility of occupational illness and injury has shown statistically significant association with PPE utilization. The study showed that as a unit increase in total score of perceived susceptibility the odds of utilizing PPE was also increased by $20 \%$. This finding is in line with different studies conducted in USA and Thailand $[28,30]$. This might be explained as the study participants those having high susceptibility may belief that using PPE has the potential to protect work related disease and injuries. Similarly as a unit increases in total score of perceived severity the odds of using PPE was increased by $10 \%$. This finding is consistent with the studies conducted in Indonesia and USA. This might be due to the 
workers beliefs about the seriousness of the occupational illness, injury and possible outcome of the disease. The other explanation may be high perceived susceptibility and severity towards occupational illness and injury may also increase the perceived threat of respondents; thus the participants could use PPE. In general, workers who perceived as they are highly susceptible to work related illness \& injury and that they perceived work related disease is a serious disease, they would be more likely to utilized PPE.

The other predictor variable towards PPE utilization was perceived barrier, it was significantly associated with PPE utilization and it indicated that as a unit increases in sum score of perceived barriers the odds of using PPE was decreased by $13 \%$. Similar finding was reported from cross-sectional study conducted in Hawassa and Nigeria that showed barriers like inconvenience, unavailability, and increased cost were found to be predictors of PPE utilization[55, 56].

Self-confidence in using PPE [perceived self-efficacy] was found to be a significant predictor of PPE utilization, in which, per a unit increases in the total score of perceived self-efficacy towards PPE utilization the odds of using PPE was increased by $20 \%$, [AOR $=1.2,95 \%, \mathrm{Cl}$ [1.082-1.349]]. The possible justification might be People with high self-efficacy show elevated confidence in their skills and have no doubt about themselves. In these cases, factory workers consider the problems as a challenge, not a threat, and they actively search for new situations. In addition, high self-efficacy reduces fear of failure, increases the level of motivation, and improves problem-solving and analytical thinking abilities. In the same way, high self-efficacy in working a hazardous environment may promote the use of PPE.

On the other hand, Perceived benefit [AOR $=1.05,95 \%, \mathrm{Cl}[0.95-1.17, \mathrm{P}=.302]]$ were not found to be predictors of PPE utilization. This finding was in line with the study done in USA, in which Perceived benefit towards using PPE was not found to be independent predictors. Similarly cues to action were not predictors of PPE utilization. The finding is inconsistent with the study done in Indonesia to identify factors influencing the use of PPE [[OR $=7.17 ; 95 \% \mathrm{Cl}=2.17$ to $23.62 ; \mathrm{p}=0.001]$. This inconsistency may be due to the difference of educational level, media exposure and culture of the participants.

\section{Conclusion}

The finding revealed that good PPE utilization among large-scale workers. Perceived susceptibility, Perceived severity, perceived self-efficacy and Perceived barrier were found to be strong predictors of PPE utilization.

\section{Limitation Of The Study}

Since the study is cross sectional it does not show cause and effect relationship between dependent and independent variables.

\section{Recommendations}


- For Health professionals delivering health education or health information to increase personal protective equipment utilization should provide special emphasis to susceptibility and severity of occupational disease and injuries.

- For Regulatory bodies, workers association and other stake holders working to increase personal protective equipment utilization should focus on modification of barriers and increasing selfconfidence of workers in using PPE.

- For factory managers in order to increase personal protective equipment utilization focus on reducing barriers of PPE utilization.

\section{Abbreviations}

PPE: Personal protective equipment, HBM: Health belief model, OSHA: Occupational Health and Safety Act.

\section{Declarations}

\section{Ethics approval and consent to participate}

Ethical clearance was obtained from the Institution Review Board of Debre Berhan University with a protocol number of $28 / 21 / \mathrm{CHS} / \mathrm{SPH}$. All participants of the study provided with informed verbal consent, clearly stating the objectives of the study and the right of study participants. All participants were randomly selected without any discrimination and filled out questionnaires were carefully handled and all access to results kept strictly.

\section{Availability of data and materials}

The data collected for this study can be obtained from the first or last author upon a reasonable request.

\section{Funding}

This research received no specific grant from any funding agency in the public, commercial or not-forprofit sectors.

\section{Acknowledgements}

We would like to thank study participants and data collectors for their unreserved contribution.

\section{Competing interests}

The authors declare that they have no competing interests.

\section{Consent for publication}

Not applicable 


\section{Authors' contributions}

Authors involved in designing, proposal writing, data collection, analyzing the data, drafted the first version of manuscript, and participated in all phases of the project. All authors read and approved the final version of the manuscript before submission.

\section{References}

1. Safety O, Administration H. Personal protective equipment. US Department of Labor Regulations: OSHA; 2016.

2. Ahmed SM, et al., Addressing the issue of compliance with personal protective equipment on construction worksites: A workers' perspective. 2015.

3. Jafaralilou $\mathrm{H}$, et al. The impact of theory-based educational intervention on improving helmet use behavior among workers of cement factory, Iran. J Egypt Public Health Assoc. 2019;94[1]:1-7.

4. Munyua FW. Factors influencing use of personal protective equipment [PPE's] by motor vehicle repair workers in Kigandaini, Thika. University of Nairobi; 2017.

5. Baksh K, Ganpat W, Narine L. Farmers knowledge, attitudes and perceptions of occupational health and safety hazards in Trinidad, West Indies and implications for the Agriculture sector. Journal of Agricultural Extension and Rural Development, 2015. 7[7]: p. 221-228.

6. Bakhsh $\mathrm{K}$, et al. Health hazards and adoption of personal protective equipment during cotton harvesting in Pakistan. Sci Total Environ. 2017;598:1058-64.

7. Alamneh YM, et al. The prevalence of occupational injury and its associated factors in Ethiopia: a systematic review and meta-analysis. Journal of Occupational Medicine Toxicology. 2020;15[1]:111.

8. Tadesse S, Kelaye T, Assefa Y. Utilization of personal protective equipment and associated factors among textile factory workers at Hawassa Town, Southern Ethiopia. Journal of Occupational Medicine and Toxicology, 2016. 11[1]: p. 6.

9. Demeke A. Assessment of the utilization of personal protective equipment among textile industry Workers in Dukem Town. Addis Ababa University; 2017.

10. Gebremichael G, Kumie A. The prevalence and associated factors of occupational injury among workers in Arba Minch textile factory, southern Ethiopia: a cross sectional study. Occupational medicine and health affairs, 2015. 3[6]: p. e1000222-e1000222.

11. JUKKA TAKALA, et al., Burden of Injury and IIIness at Work in Selected Contries and Regions. Central European Journal of Occupational and Environmental Medicine, 2017. 23 [7]: p. 1-2.

12. Hämäläinen P, Takala J, Kiat TB. Global estimates of occupational accidents and work-related illnesses 2017. World. 2017;2017:3-4.

13. Pratik K, Jasani*, et al., A study of knowledge and utilization of safety measures against occupational hazards among workers in Surendranagar city, Gujarat, India. International Journal of 
Community Medicine and Public Health 2016.

14. Labor TMo. National policy on Occupational Health and Safety. Namibia: Windhoek; 2016.

15. Chepkener AC. Knowledge, Attitude And Practice Of Eye Safety Among Jua Kali Industry Workers In Nairobi, Kenya. University of Nairobi; 2013.

16. Zegeorgous KG, et al., Utilization of personal protective equipment and associated factors among Kombolcha Textile Factory workers, Kombolcha, Ethiopia: A cross-sectional study. J Public Health, 2020. 7[100025P16KZ2020]: p. 100025P16KZ2020.

17. Wall J, Development of a health-belief-modelbased instrument to assess worker beliefs about using personal protective equipment. The University of Utah. 2009, Master Thesis. Utah.

18. O., O.K., E.J. E., and Hosea O. Utilization of Personal Protective Equipments [PPEs] among Wood Factory Workers in Calabar Municipality, Southern Nigeria 2017: p. 1.

19. ILO. The Prevention of Occupational Diseases: World Day for safety and health at work 28 April 2013. Switzerland: International labour Office Geneva; 2013.

20. RrDianTristiana RatihPravitasari, ErnaDwiWahyuni. Contributing Factors of Personal Protection Equipment [PPE] Utilization among Sandand Gravel [SSG] Mine Workers. International Journal o fPsychosocial Rehabilitation 2020. 24[7].

21. Labour Proclamation. in 89. FEDERAL NEGARIT GAZETTE OF THE FEDERAL DEMOCRATIC REPUBLIC OF ETHIOPIA: Addis Ababa. p. 11691.

22. Duguma* FK, et al., Assessment of Safety Equipment Utilization Rate and Magnitude of Occupational Related Incidences Among Workers in the Ministry of Defense Construction CMC Site, Addis Ababa, Ethiopia. Civil Eng Res J 2018. 9[2].

23. SR A. Utilization Pattern of Personal Protective Equipment among Industrial Workers of Nawalparasi, Nepal. Journal of Public Healt, 2014. 13 I[ Issue II ].

24. Izudi J, Ninsiima V, Alege JB, Use of personal protective equipment among building construction workers in Kampala, Uganda. Journal of environmental and public health, 2017. 2017.

25. Dewi RD, Rahardjo SS, Murti B. Application of Health Belief Model on Factors Influencing the Use Of Personal Protective Equipment. in 6th International Conference on Public Health 2019. Sebelas Maret University.

26. KYALO AM. LEVEL OF UTILIZATION OF PERSONAL PROTECTIVE EQUIPMENT AMONG WORKERS IN GRAIN AND OIL SEED MILLING INDUSTRIES IN NAIROBI CITY COUNTY, KENYA. KENYATTA UNIVERSITY; 2016.

27. Muema LM. Evaluation of Personal Protective Equipment Utilization among Construction Workers in Mombasa County, Kenya. JKUAT: COHES; 2017.

28. Wright $\mathrm{T}$, et al., Issue of compliance with use of personal protective equipment among wastewater workers across the southeast region of the United States. International journal of environmental research and public health, 2019. 16[11]: p. 2009. 
29. Damalas CA, Abdollahzadeh G. Farmers' use of personal protective equipment during handling of plant protection products: Determinants of implementation. Science of The Total Environment. 2016;571:730-6.

30. Panakobkit W, Sakunkoo P, CHamroen P. Health Belief Model and Behavioural Usage of Respiratory Protective Equipment among Sugarcane Workers in Northeast of Thailand: A Cross-sectional Analytical Study. Journal of Clinical \& Diagnostic Research; 2019. 13[12].

31. Kralam K, Taneepanichskul N, Knowledge, Attitude and Practice towards Personal Protective Equipment Use among Steel Industry Workers in Thailand. Journal of Health Research, 2016. 30[Suppl. 2]: p. S161-S165.

32. Dita M, et al., The Correlation Between Knowledge About Occupational Accidents and Safe Work Behaviors Among Employees at the Production Division of PT X Indonesia. KnE Life Sciences, 2019: p. 123-131-123-131.

33. Umoren QM, et al., An assessment of the effect of health education on the use of personal protective equipment among small scale welders [panel beaters] in Akwa Ibom state, Nigeria. International Journal of Community Medicine and Public Health, 2016. 3[11]: p. 3220-3228.

34. Johnson $\mathrm{OE}$, Motilewa 0O. Knowledge and use of personal protective equipment among auto technicians in Uyo, Nigeria. Journal of Education, Society and Behavioural Science, 2016: p. 1-8.

35. Beyene Gebrezgiabher B, Tetemke D, Yetum T, Awareness of occupational hazards and utilization of safety measures among welders in Aksum and Adwa towns, Tigray region, Ethiopia, 2013. Journal of environmental and public health, 2019. 2019.

36. Orji R, Vassileva J, Mandryk R. Towards an effective health interventions design: an extension of the health belief model. Online journal of public health informatics, 2012. 4[3].

37. Dewantara BP, Murti B, Widyaningsih V. Application of Health Belief Model and Social Cognitive Theory on the Use of Personal Protective Equipment among Workers at the Plywood Plant: Path Analysis Evidence from Lumajang, East Java. Journal of Health Promotion and Behavior, 2019. 4[4]: p. 306-318.

38. Sari NK, Rahardjo SS, Widyaningsih V. Factors associated with personal hygiene, use of personal protective equipment, and the risk of contact dermatitis among scavengers: A path analysis evidence from Surakarta, Central Java. Journal of Health Promotion and Behavior, 2019. 4[3]: p. 198-211.

39. Sharifzadeh MS, Damalas CA, Abdollahzadeh G. RETRACTED: Perceived usefulness of personal protective equipment in pesticide use predicts farmers' willingness to use it. Elsevier; 2017.

40. Okello T, et al., Barriers and factors affecting personal protective equipment usage in St. Mary's Hospital Lacor in Northern Uganda. East and Central African Journal of Surgery, 2017. 22[1]: p. 5965.

41. Alemu AA, et al. Utilization of personal protective equipment and associated factors among building construction workers in Addis Ababa, Ethiopia, 2019. BMC Public Health. 2020;20:1-7.

42. Hou S-I. Health education: theoretical concepts, effective strategies and core competencies. Health promotion practice, 2014. 15[5]: p. 619-621. 
43. DeJoy DM. Theoretical models of health behavior and workplace self-protective behavior. J Saf Res. 1996;27[2]:61-72.

44. Nisbet EK, Gick ML. Can health psychology help the planet? Applying theory and models of health behaviour to environmental actions. Canadian Psychology/Psychologie canadienne, 2008. 49[4]: p. 296.

45. Ridley JR, Channing J. Workplace safety. Butterworth-Heinemann; 1999.

46. Bello SR. WORKPLACE HAZARDS2012, North Charleston, SC 29418 US: Dominion Publishing Services.

47. ILO. Safety and health Tthe heart of future work: Building on 100 years of experience. Labour Inspection: Geneva 22 Switzerland: Labour Administration; 2019.

48. Meusburger P, Werlen B, Suarsana L. Knowledge and action. Springer Nature; 2017.

49. Health UDo, Services $H$. Theory at a glance: a guide for health promotion practice. Lulu. com; 2005.

50. Jasani PK, et al. A study of knowledge and utilization of safety measures against occupational hazards among constructional workers in Surendranagar city, Gujarat, India. Int J Commun Med Public Health. 2016;3:3055-8.

51. Esaiyas A, Sanbata H, Mekonnen Y. Occupational Health and Safety Related Knowledge, Attitude and Practice among Wood and Metal Workers in Hawassa, Ethiopia. Annual Research \& Review in Biology; 2018. pp. 1-9.

52. Ramos AK, Fuentes A, Trinidad N. Perception of job-related risk, training, and use of personal protective equipment [PPE] among Latino immigrant hog CAFO workers in Missouri: A pilot study. Safety, 2016. 2[4]: p. 25.

53. Acharya SR, Utilization pattern of personal protective equipment among industrial workers of Nawalparasi, Nepal. Health Prospect: Journal of Public Health, 2014. 13[2]: p. 24-27.

54. Dewi RD, Rahardjo SS, Murti B. Application of Health Belief Model on Factors Influencing the Use Of Personal Protective Equipment.". in 6th International Conference on Public Health 2019, Surakarta, Indonesia, October 2019. 2019.

55. Osonwa Kalu O, Jimmy EE, Ozah H. Utilization of personal protective equipments [PPEs] among wood factory workers in Calabar Municipality, Southern Nigeria. Age, 2015. 15[19]: p. 14.

56. Tadesse S, Kelaye T, Assefa Y. Utilization of personal protective equipment and associated factors among textile factory workers at Hawassa Town, Southern Ethiopia. Journal of Occupational Medicine Toxicology. 2016;11[1]:1-6.

\section{Figures}




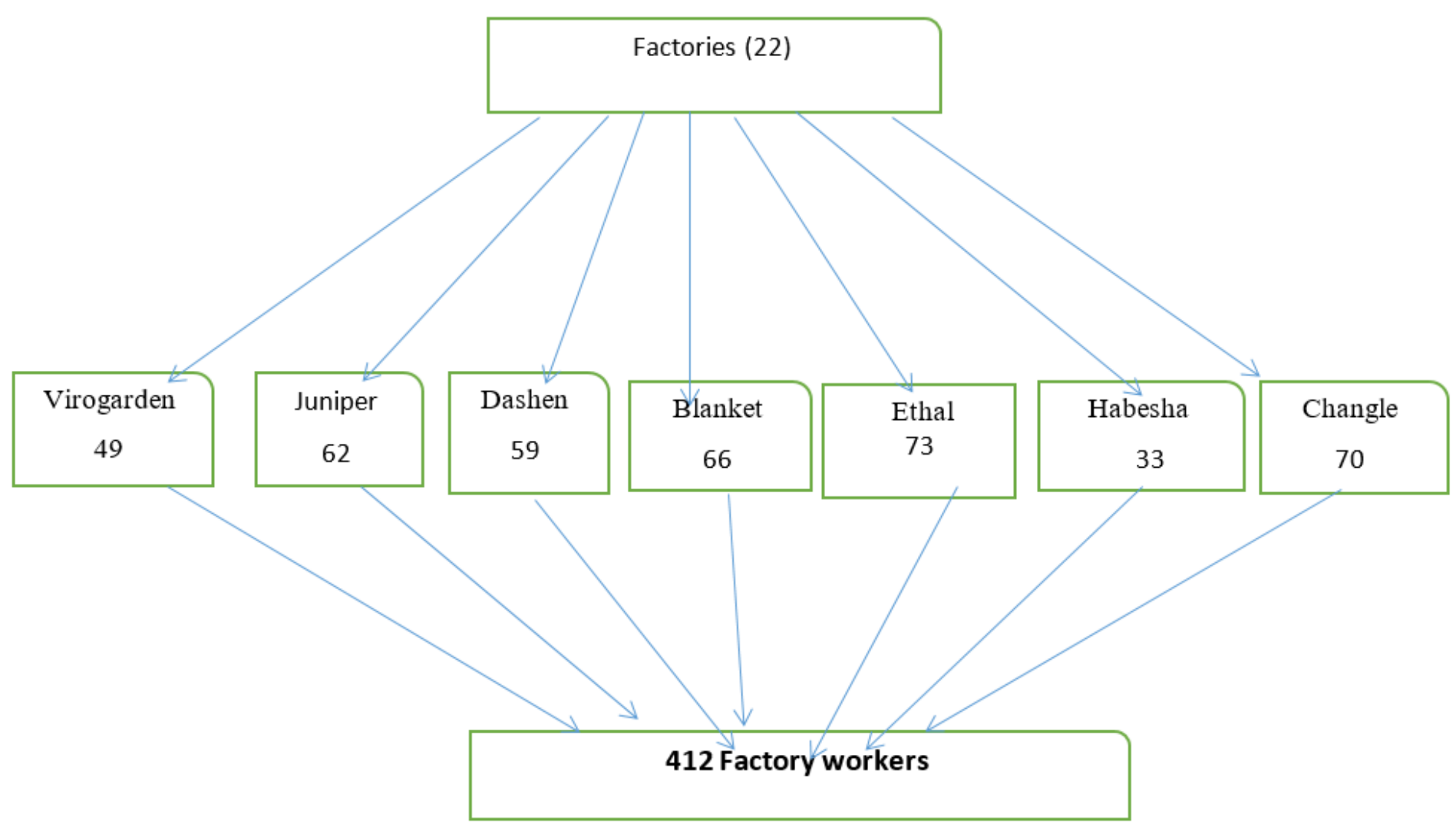

\section{Figure 1}

Schematic presentation of sampling procedure for PPE utilization and associated factors among large scale factory workers in Debre-Birhan town, 2021. 


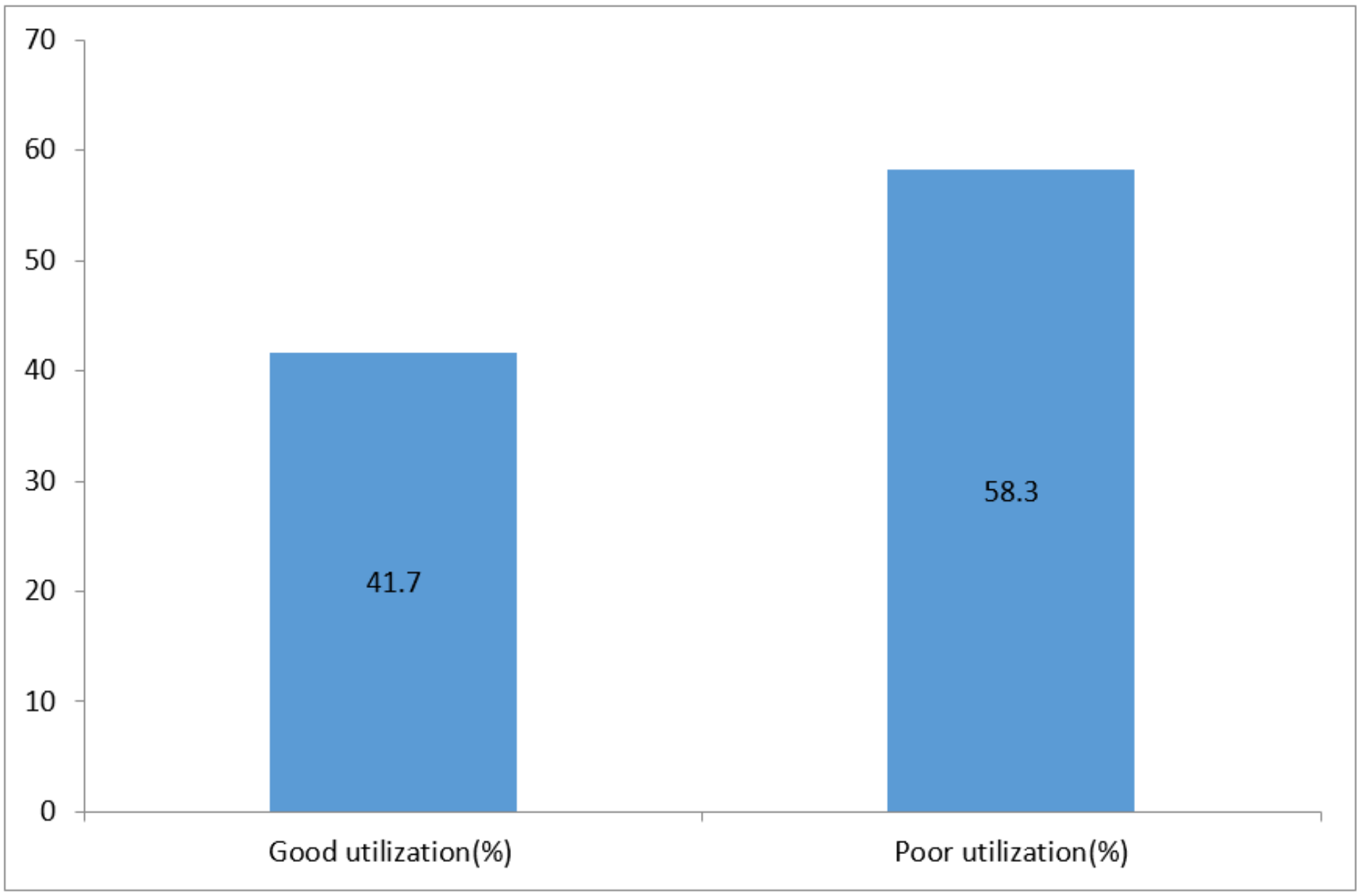

Figure 2

PPE utilization of large scale factory worker in Debre-Birhan Town, Ethiopia. June, 2021.

\section{Supplementary Files}

This is a list of supplementary files associated with this preprint. Click to download.

- SF1.EnglishversionQuestionnaire.docx

- SF2.AmharicversionofQuestionnaire.docx 